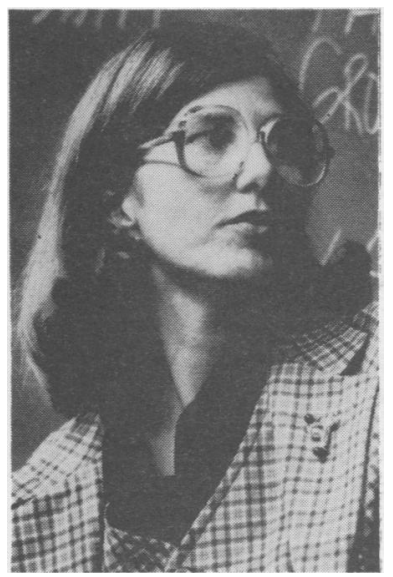

\title{
STRENGTH AND FLEXIBILITY IN GYMNASTS BEFORE AND AFTER MENARCHE
}

KATHLEEN M. HAYWOOD, PhD

Department of Physical Education, University of Missouri - St. Louis, St. Louis, Missouri

\begin{abstract}
Simple anthropometric measures, flexibility, and strength performance tests were conducted on 30 young gymnasts and repeated one year later. During the intervening year, 13 gymnasts, average age 14.5 at the second year, reached menarche, while the remaining 17, average age 14.1 years, did not. Multivariate analyses of covariance were calculated to test for differences between the groups at Year 2, using the Year 1 scores as covariates. No significant differences between the groups were found. Tendencies to linearity of physique and late maturation, noted in the literature among very skilled gymnasts, seemed to be confirmed among this group of local competitors.
\end{abstract}

KEYWORDS: Menarche, gymnasts, anthropometry.

\section{INTRODUCTION}

The dominant theme of motor development in childhood and adolescence in regard to many variables, such as strength or muscle endurance, has been that with physical growth comes an improvement in motor performance. An exception has been some measures of motor performance by adolescent girls after puberty. For example, the mean time for the $600 \mathrm{Yard}$ Run in the AAHPER Youth Fitness Test (1976) rose after age 15 in both the 1975 and 1965 scores. Of course, these data have often included a cross-section of adolescent girls, many of whom are less active in later adolescence. More than ever before, adolescent girls are now maintaining vigorous training throughout adolescence. While we know that girls accumulate body fat at puberty, we have little data on the changes in strength and flexibility which may accompany physical changes around the time of menarche, especially in girls maintaining vigorous training.

The purpose of this study was first, to compare the performance on strength and flexibility tasks of a group of gymnasts who have reached menarche with that of a group who have not, and second, to report the approximate age of menarche for girls participating seriously in gymnastics but only at the local level.

\section{SUBJECTS}

The subjects of this study were tested during a week- long gymnastics school at the University of Missouri-St. Louis held in 1978, 1979, and 1980, but all were members of local gymnastics clubs and participated in the sport year-round. Thirty of the gymnasts between 12.3 and 14.5 years of age tested in 1978 or 1979 returned to the school one year later. During the intervening year, 13 of the gymnasts reached menarche and 17 did not. The pre-menarche group averaged 14.1 years of age $(S D=.5)$ in Year 2 while the post-menarche group averaged 14.5 years $(S D=.5)$. The gymnasts were placed in one of 5 ability levels with " 5 " being the most skilled. The pre-menarche gymnasts were placed at an ability level which averaged 4.2 and the post-menarche gymnasts 4.3. Although the number of girls tested is small, this occurrence offered a unique opportunity to look at anthropometric, flexibility, and strength measures in these groups which were close in age and skill level. The post-menarche gymnasts reported that they trained an average of 8.0 hours/week while the premenarche gymnasts reported training 6.8 hours/week.

\section{METHODS}

The anthropometric measures taken on the gymnasts were standing height, body weight, upper arm girth. A triceps skinfold and subscapular skinfold measure were also taken with Lange callipers. Three measurements were made at each site and the average taken. Lean body mass and relative fat were estimated from the equation for young boys determined by Lohman, Boileau, and 


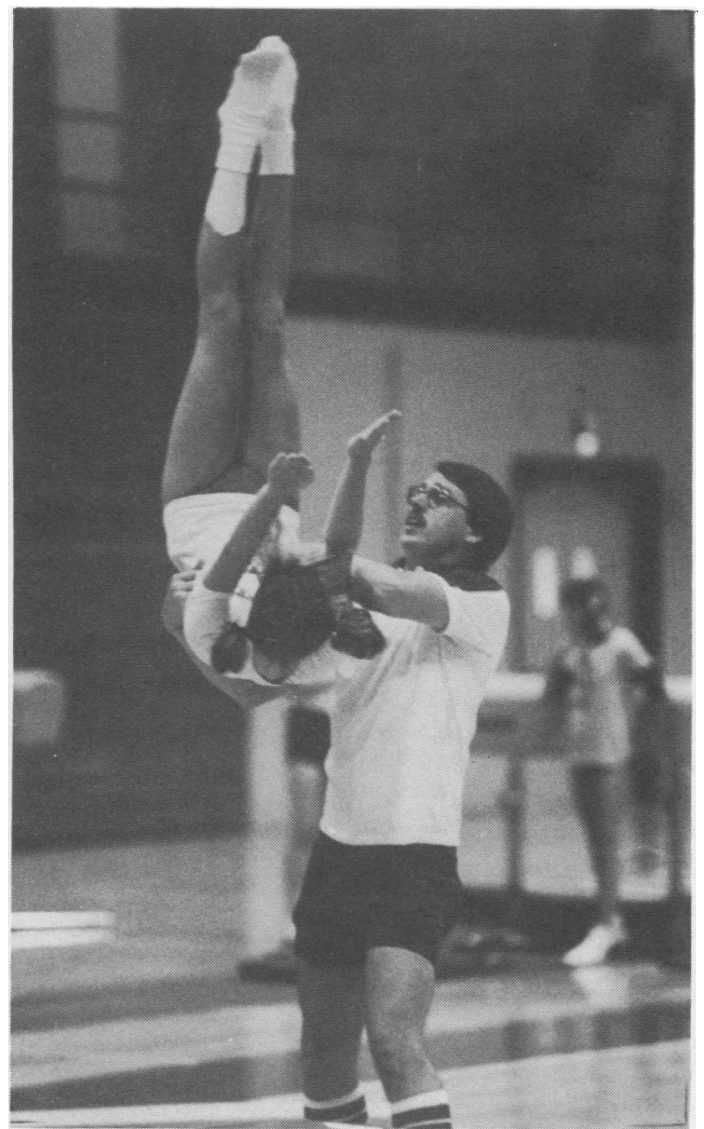

Massey (1975). Although there may be minor differences between the sexes before puberty, this equation has been shown effective when used with young girls (Rizzo, 1977). One may question whether any single equation is appropriate for measures both before and after menarche, so the lean body mass and percent body fat measures must be interpreted in this light. However, the emphasis here was on within-subject comparisons.

Strength testing was performed in two categories: specific and general. The specific tests measured the pulling strength of the arm in three positions. The test, originally described by Faulkner (1962), is a modification of the arm depressor exercise described by Counsilman (1968). Measurements were made at 3 positions using a cable tensiometer apparatus with the subject in a kneeling position. The positions and angles at the elbow were (1) overhead $125^{\circ}$, (2) chest level $110^{\circ}$, and (3) waist level $135^{\circ}$. The best of 3 trials at each position was used to represent a given position.

General tests for muscle strength, power, and flexibility were given. Strength and power evaluation in- cluded measurement of dominant and non-dominant grip strength, and vertical jump. The grip of a hand dynamometer was set for hand size with 3 trials given for each hand. Maximum readings were used. The vertical jump was performed as described by Mathews (1973) and the sit-ups and flexed arm hang as described in the AAHPER Youth Fitness Test (1976). Flexibility was determined for ankle plantar-dorsiflexion, as described by Munroe and Romance (1975) and trunk flexibility was evaluated as noted in Mathews (1973).

\section{RESULTS AND DISCUSSION}

Four multivariate analyses of covariance were calculated to test for differences between the groups at Year 2, using the Year 1 scores as covariates. The four analyses were conducted on the anthropometric variables, the flexibility variables, the arm and shoulder strength variables, and on the remaining strength variables. As the summary statistics show (Table I) there was no significant difference between the two groups in any case. Therefore, when any differences between the groups before menarche were equalised by the covariance treatment, there were no significant differences between the groups, similar in age and skill but different in whether or not menarche was reached. This maturational landmark appeared to have little significant effect on the strength and flexibility of the present girls, who maintained training levels and participation throughout the year between testing.

\section{TABLE I}

\section{MANOVA summary statistics, "group" main effect}

$\begin{array}{lcccc}\text { Dependent Variable Group } & \begin{array}{c}\text { Wilk's } \\ \text { Criterion }\end{array} & \text { F } & \text { df } & \text { p } \\ \text { Anthropometric Variables } & .58 & 1.30 & 6,11 & .33 \\ \text { Flexibility Variables } & .94 & 0.70 & 2,23 & .51 \\ \begin{array}{l}\text { Arm, Shoulder Strength } \\ \quad \text { Variables }\end{array} & .98 & 0.09 & 4,17 & .99 \\ \text { Remaining Strength Variables } & .81 & 1.02 & 4,17 & .42\end{array}$

Several trends in the mean scores of the groups (Table II) are worthy of note. First, the absolute performance and anthropometric measures of the "post" gymnasts decreased slightly on flexed arm hang performance but improved on the specific arm-and-shoulder strength tests. The former, of course, requires support of the body weight which increased for the group over the year. The post-menarche gymnasts also maintained their percent body fat while the pre-menarche gymnasts actually declined in this measure. Secondly, both groups tended to improve slightly in trunk flexibility but declined in ankle flexibility. The latter probably reflects a deficiency of the regular training programme used by most of the gymnastic clubs. 
TABLE ॥

Mean scores of pre- and post-menarche gymnasts at Year 1 and Year 2

Moasure

Height $(\mathrm{cm})$

Weight $(\mathrm{kg})$

Arm Girth $(\mathrm{cm})$

Waist Girth $(\mathrm{cm})$

Lean Body Mass $(\mathrm{kg})$

Percent Body Fat

Ankle Flexibility (deg)

Trunk Flexibility $(\mathrm{cm})$

Vertical Jump (cm)

Dominant Handgrip ( $\mathrm{kg}$ )

Nondominant Handgrip (kg)

Flexed Arm Hang (sec)

Sit-Ups

Overhead Specific Strength (kg)

Chest Level Specific Strength (kg)

Waist Level Specific Strength (kg)

\begin{tabular}{|c|c|}
\hline \multicolumn{2}{|c|}{ Year 1} \\
\hline $\begin{array}{l}\text { Pre-Menarche } \\
\text { Gymnasts }\end{array}$ & $\begin{array}{l}\text { Post-Menarche } \\
\text { Gymnasts }\end{array}$ \\
\hline
\end{tabular}

148.8

37.5

22.7

58.6

29.3

22.0

71.8

63.3

38.7

24.2

22.6

20.7

42.4

97.4

29.5

65.1

$$
\begin{array}{r}
154.0 \\
43.1 \\
23.7 \\
62.6 \\
33.3 \\
22.7 \\
72.9 \\
67.6 \\
41.2 \\
26.1 \\
25.8 \\
18.5 \\
42.3 \\
102.7 \\
35.3 \\
72.4
\end{array}
$$

Year 2

$\begin{array}{cc}\begin{array}{c}\text { Pre-Menarche } \\ \text { Gymnasts }\end{array} & \begin{array}{c}\text { Post-Menarche } \\ \text { Gymnasts }\end{array}\end{array}$

157.7

47.4

24.8

63.2

36.5

22.9

68.6

68.9

43.5

28.6

28.0

18.2

42.7

123.6

38.5

79.2
The small stature and light weight of skilled gymnasts has been noted in the literature, as well as their tendency to reach menarche later than average. In Year 2 the present pre-menarche gymnasts were below the 25th percentile for their age for stature and the postmenarche gymnasts slightly above the 25th percentile. The same was true for weight. Malina, Bouchard et al (1979) noted that gymnasts participating in the Montreal Olympic games were 14.5 years of age, on the average, at menarche. The median age at menarche in the United States is 12.8 years. On the average, the "post" group reached menarche between 13.5 and 14.5 years of age, while of course, none of the "pre" group had reached menarche by an average of 14.1 years. This study therefore extends the trend toward linearity of physique and later maturation among skilled gymnasts to girls engaged in gymnastics at the local level.

Frisch and McArthur (1974) have determined that the minimal weight for a particular height for onset of menstrual cycles is indicated by the 10th percentile of fractional body water at menarche. If the Year 1 weightfor-height values for the present two groups of gymnasts are calculated, it is found that the group mean of the "pre" group is only slightly above this 10th percentile value as determined by Frisch and McArthur.

In summary, adolescent girls of this sample participating seriously in gymnastics but at a local level tend to be short and light for their age and tend to be late maturers. No evidence has been found that gymnasts in training decline in their performance on strength and flexibility tasks after menarche compared to premenarche gymnasts of similar age and skill.

\section{ACKNOWLEDGEMENT}

The help of Dr. Bruce Clark and Robert Oppliger for designing the test battery, Dr. Gary Burger for statistical advice, Harold Mack for computer assistance, and Carol McAlister and Cathy Lewis for assistance in testing is gratefully acknowledged.

\section{REFERENCES}

Counsilman, J. E., 1968 "The science of swimming". Prentice-Hall: Englewood Cliffs.

Faulkner, J. A., Greey, G. and Hunsicker, P. A., 1962 “Grand Rapids: Evaluation of the health and physical education programme, 1961-1962". Ann Arbor Michigan, Bureau of School Services.

Frisch, R. and McArthur, J., 1974 "Menstrual cycles: Fatness as a determinant of minimum weight for height necessary for their maintenance and onset". Science, 185: 949-951. 
Lohman, T. G., Boileau, R. A. and Massey, B. H., 1975 "Prediction of lean body mass in young boys from skinfold thickness and body weight". Human Biology, 47: 245-262.

Malina, R. M., Bouchard, C., Shoup, R., Demirjian, A. and Lariviere, G., 1979 "Age at menarche, family size, and birth order in athletes at the Montreal Olympic Games, 1976". Medicine and Science in Sports, 11: 354-358.

Mathews, D. K., 1973 “Measurement in physical education”. (4th edition). W. B. Saunders Co: Philadelphia.

Munroe, A. and Romance, T. J., 1975 “Use of the Leighton Flexometer in the development of a short flexibility test battery". American Corrective therapy Journal, 29: 22-25.

Rizzo, C. G., 1977 "Prediction of lean body mass in young girls from skinfold thickness and body weight". Master's thesis, University of Illinois.

American Assocation for Health, Physical Education and Recreation, 1976 "Youth fitness test manual". Washington.

\section{BOOK REVIEW}

Title: $\quad$ A COLOUR ATLAS OF INJURY IN SPORT

Author: $\quad$ J. G. P. Williams, 1980

Publisher: $\quad$ Wolfe Medical Publications Ltd., London

Price: $£ 15.00 \quad 152$ pages including index 504 figures

For all those who have been entranced by the slides shown at various meetings and courses all over the world by John Williams, this Atlas will come as a very welcome reminder of the many conditions shown briefly by the projector, and a chance can be taken to study them in detail. The coloured photographs are excellent, and the radiographs are reproduced well enough for the lesions illustrated to be observed by those relatively inexperienced in the interpretation of X-Rays.

The book begins with a discussion on the nature of injury, needing an understanding of the mechanism that leads to tissue damage. The section on the classification of injury by causal factors is not set out well by the printer; the table is split between two columns, which could have been avoided, and the use of italics and bold type would have made the subdivisions clearer to those unfamiliar with the injury classification. A few other minor criticisms can be made, for consideration in the next edition; the scapulo-humeral rhythm is illustrated in an over-simplified manner (page 138), the significant imprinting of clothing, tyres or horseshoes is omitted when discussing abdominal injuries, and coccygeal injuries are noted as being rare (though 1 have had two equestrian injuries from hitting the cantle of the saddle, and one case of coccydynia in a girl landing on a hard floor doing a standard broad jump in general practice this year). Operations for tendon decompression may not find favour with all orthopaedic surgeons, but they generally are successful, and well illustrated in the atlas.

This book will be a useful introduction to sports medicine for any doctor, general practitioner or specialist, who deals with injuries in sport or in sportsmen, and to physiotherapists, teachers and those caring for sportsmen who should be aware of the mechanism of injury, ways of prevention and recognition of abnormal conditions that need expert treatment. All atlases are now expensive, but at $£ 15$ this one seems excellent value.

H. E. Robson 